\title{
PATTERNS OF ALTERNATIVE TOBACCO PRODUCT EXPERIMENTATION AMONG EVER SMOKER ADOLESCENTS
}

\author{
Melinda Pénzes ${ }^{1}$, Kristie L. Foley², Péter Balázs'1 , Róbert Urbán ${ }^{3}$ \\ ${ }^{1}$ Institute of Public Health, Faculty of Medicine, Semmelweis University, Budapest, Hungary \\ 2Department of Implementation Sciences, Wake Forest School of Medicine, Winston-Salem, North Carolina, USA \\ ${ }^{3}$ Institute of Psychology, Eötvös Loránd University, Budapest, Hungary
}

\begin{abstract}
SUMMARY
Objectives: Alternative tobacco product (ATP) use is popular among adolescents in Western countries, however, little is known about factors influencing ATP experimentation in Europe. The aim of this study was to explore factors associated with ATP experimentation, and to identify patterns of ATP experimentation among Hungarian adolescents who had ever tried manufactured cigarette smoking.

Methods: Logistic regression analyses were applied to estimate the relationship between individual cigarette smoking experiences, social smoking influences, demographics, and ATP experimentation (roll-your-own (RYO) cigarettes, cigars/cigarillos, waterpipe, traditional pipe and flavoured cigarettes) in a cross-sectional sample of 8 th and 11 th grade students ( $N=1,067,56.0 \%$ of girls) who had ever tried manufactured cigarette smoking in six metropolitan cities of Hungary. Latent class analysis (LCA) was performed to identify patterns of different ATP use.

Results: Almost $90 \%$ of the sample had ever tried ATPs and significantly more commonly older (91.8\%) versus younger (79.8\%) students. Waterpipe was the most popular product to try followed by flavoured cigarettes, cigars/cigarillos, RYO cigarettes, and pipe. Boys were more likely to report ATP experimentation compared to girls. Younger age of cigarette smoking experimentation, greater frequency of past month cigarette smoking and history of ever daily smoking for 30 days showed strong association with ATP experimentation. Students with one or more smoking friends were more vulnerable to experiment with ATPs. Weekly allowance, school academic achievement and household smoking exposure showed no effect on the experimentation. LCA identified four subgroups of ATP experimenters comprising intense polytobacco experimenters (38.4\%), mainly waterpipe experimenters (34.2\%), moderate polytobacco experimenters (14.9\%), and less interested experimenters (12.5\%).

Conclusion: Tobacco prevention programmes targeting adolescents should emphasize the risks of using ATPs in addition to manufactured cigarettes. Accessibility of ATPs should be better regulated and restrictions should be strongly enforced in order to prevent potential harmful consequences of adolescent polytobacco use.
\end{abstract}

Key words: adolescent, tobacco, alternative tobacco products, smoking, latent class analysis

Address for correspondence: M. Pénzes, Institute of Public Health, Faculty of Medicine, Semmelweis University, Üllöi út 26, H-1085 Budapest, Hungary. E-mail: melindapenzes@gmail.com

https://doi.org/10.21101/cejph.a5364

\section{INTRODUCTION}

Alternative tobacco products (ATPs) are generally referred as all tobacco products other than manufactured cigarettes that incorporate tobacco-constituent. Combustible ATPs may include waterpipe, cigar, cigarillo, roll-your-own (RYO) cigarette, flavoured cigarette, bidi, and kretek while non-combustible or smokeless tobacco products are for instance snus and snuff $(1-4)$. There is a risk continuum among varied combustible and non-combustible ATPs, and there is a considerable dearth of information on the long-term risks of products that are new to the market (e.g. ecigarettes). Risk continuum concept implies a spectrum of tobacco products from most to least risk on human health at individual and population level. On risk continuum, manufactured cigarettes are the most harmful followed by non-cigarette combustibles and non-combustible ATPs (4).

Public policy and research on adolescent tobacco use has predominately focused on manufactured cigarettes, although in- creasing attention is aimed at ATPs given their rising prevalence among youth (5). The use of ATPs by adolescents is widespread especially in the Eastern Mediterranean and African regions of the world and least typical in the European region, however, recent studies show that the popularity of ATPs is increasing among both European and American adolescents $(5,6)$. Reasons for the gain in popularity are diverse. There is a global increase in stronger regulation and social disapproval of cigarette smoking, but regulations regarding the availability, marketing and advertising of ATPs are often insufficient $(1,6,7)$. Youth and adults perceive ATPs as less harmful tobacco products compared to manufactured cigarettes (1, 6), even though both ATPs and polytobacco use might lead to or reinforce manufactured cigarette smoking and nicotine dependence and increase the risk of other adverse health consequences $(4,8,9)$. Several other factors can also encourage young people to use ATPs. Many adolescents consider ATPs as attractive, something exciting new, unlike cigarette smoking which is increasingly perceived as unattractive and socially non-normative $(10,11)$. 
Flavourings also increase the attractiveness of ATPs given that flavoured tobacco products are easier to use as flavours can mask the harshness of tobacco (10-12). Peer pressure and noveltyseeking friends also have impact on ATP experimentation $(3,13$, 14). Additional motives for using ATPs could be the lower costs of certain ATPs (especially RYO cigarettes) as an important factor for price-sensitive youth $(15,16)$. It should also be considered that changing immigration patterns and cultural shifts in Europe and the USA may influence resident adolescent population's ATP use and help them to adopt a perception of ATPs as socially more acceptable than manufactured cigarettes (6).

Comprehensive data on the prevalence of ATP use by European adolescents are limited. Based on the results of the Global Youth Tobacco Surveys (GYTS) in Europe, past month use of any form of tobacco other than cigarettes among adolescents showed the highest rate in Latvia and Estonia while moderate prevalence was detected in countries of the Central European Region (5). Regarding Hungarian adolescents, recent national GYTS detected decreasing prevalence of past month use of ATPs (17).

Only a few studies, located mainly in the USA and one in Argentina and another in central Romania, explored risk factors of various ATP use among youth $(2,3,8,9,13,14,18,19)$, while in Europe, published studies focused primarily on the prevalence and predictors of one specific ATP use (16, 20-23). Previous studies observed that adolescent ever and current cigarette smokers are at higher risk for experimenting and using various ATPs compared to non-smoker youth $(2,3,8,13,18,19)$. Therefore, the aims of the present study were to estimate the relationship between individual cigarette smoking experiences, social smoking influences, demographic variables and ATP experimentation; and to identify patterns of different ATP experimentation among Hungarian adolescents who had ever tried manufactured cigarette smoking.

\section{MATERIALS AND METHODS}

\section{Participants and Procedure}

A cross-sectional survey was conducted during the 2011-2012 academic year in the capital of Hungary (Budapest) and five other metropolitan cities (Debrecen, Györ, Miskolc, Pécs, and Szeged). The cluster sampling involved 71 schools including elementary, vocational and high schools with 1,987 eighth and eleventh grade students (response rate $84.7 \%$ ). Parents were informed about the survey by passive consent procedure. Participants were informed verbally and in writing that their participation in the study was voluntary. Trained data collectors unknown to the students asked participants to complete the questionnaire within one teaching hour. The present study focused on respondents who ever tried manufactured cigarette smoking $(n=1,101)$. Of these, 1,067 students answered for ATP use questions (96.9\%) and form the sample of analyses for this study. The study was approved by the Institutional Review Board of Semmelweis University, Budapest.

\section{Measures}

Alternative tobacco products: Alternative tobacco product experimentation was assessed with a question: "Have you ever tried tobacco products other than manufactured cigarettes?" (with response options yes/no) including five categories of tobacco products: RYO cigarette, cigar/cigarillo, waterpipe, traditional pipe, and flavoured cigarette (described for instance as "vanilla, chocolate, mango, cherry, or clove flavoured combustible cigarettes") with dichotomous response options yes/no. Any ATP experimentation was defined as at least a single lifetime use of whichever product. Respondents were categorized as any ATP experimenters if they answered yes to any of the ATP questions, while nonusers were those who have never tried any of the ATPs.

Socio-demographic variables: We measured age, grade (8th; 11th), sex (female/male), weekly allowance in Hungarian Forint (none; $\leq 500$ HUF; 501-1,000 HUF; 1,001-1,500 HUF; 1,501-2,000 HUF; 2,001-3,000 HUF; $\geq 3,001$ HUF; 1 EUR = 310 HUF approximately, in 2018), and school academic achievement (six categories ranging from 2.00 to 5.00 with increasing values of 0.5 , in Hungary, the highest mark is 5). All covariates, except age, were incorporated in analytical models.

Manufactured cigarette smoking variables: Smoking behaviour was measured with three questions: age of the first cigarette use ( $\leq 8$ years old; from 9 to 16 years of age biennial categories; $\geq 17$ years old) which were collapsed into " 0 " $-\leq 12$ years old; "1" $-\geq 13$ years old categories; frequency of cigarette smoking in number of days during the past month $(0,1-2,3-5,6-9,10-19$, 20-29, all 30 days; respondents who smoked on at least 1 or 2 days during the past month were regarded as current smokers); and ever daily smoking for 30 days (no/yes).

Social influence variables: Social influences were indicated by the following items: household smoking ("Does anyone in your home who lives with you currently smoke cigarettes?", answered yes/no); peer smoking ("How many of your five closest friends smoke at least one cigarette a week?" with response options categorized as none of them and one or more friends).

\section{Statistical Analysis}

Bivariate and multivariate analyses were performed to test associations between ATP experimentation and socio-demographic, social influence and manufactured cigarette use variables. To understand the pattern of ATP experimentation, a latent class analysis (LCA) was performed. LCA is a latent variable analysis with categorical latent variables and categorical indicator variables (24). LCA looks for subtypes of users who exhibit similar patterns of experimentation, helping to establish clusters of different patterns of ATP experimentation. In the process of determining the number of latent classes, the Bayesian information criterion (BIC) parsimony index, the minimization of crossclassification probabilities, entropy, and the interpretability of clusters were used. In the final determination of the number of classes, the likelihood-ratio difference test - Lo-Mendell-Rubin (LMR) adjusted test, which compares the estimated model with a model with one less class than the estimated model, was also used (24). A low probability value $(\mathrm{p}<0.05)$ indicates that the model with one less class is rejected in favour of the estimated model. Multinomial logistic regression analysis was applied to understand the covariates of different patterns of ATP experimentation. Bivariate analyses were conducted with IBM SPSS 22.0 statistical software while all other analyses were performed with MPLUS 8.00 (25). 


\section{RESULTS}

Descriptive characteristics of the sample and ATP experimentation are presented in Table 1. Mean ages of 8 th and 11th grade participants were $14.2 \pm 0.6$ years and $17.2 \pm 0.7$ years, respectively. Females were overrepresented in the sample in both younger and older grades (54.0\% and $56.7 \%$, respectively).

\section{Tobacco Product Use}

Based on the original sample $(\mathrm{N}=1,987$; data not shown in Tables), more than half of adolescents (55.4\%) reported that they have ever tried manufactured cigarettes with 11 th graders in significantly higher rate than 8 th graders $(68.5 \%$ vs. $35.6 \%$, respectively; $\left.\chi_{(1)}^{2}=207.86 ; p<0.001\right)$. Fourteen percent of the younger age group and $40 \%$ of the older one smoked cigarettes in the past 30 days $\left(\chi_{(1)}^{2}=154.83 ; \mathrm{p}<0.001\right)$.

In the current subsample of adolescents who have ever tried to smoke manufactured cigarettes, almost two-thirds of participants reported past 30-day cigarette smoking (Table 1) with lower prevalence in the younger age group compared to the older one $(57.8 \%$ vs. $67.8 \%$, respectively; $\left.\chi_{(1)}^{2}=6.39 ; p=0.011\right)$. Ever daily smoking for 30 days was reported by $39.0 \%$ of the younger age group and $56.5 \%$ of the older one $\left(\chi_{(1)}^{2}=17.82 ; \mathrm{p}<0.001\right)$. Regarding ATP

Table 1. Alternative tobacco product (ATP) experimentation among participants who have ever tried cigarette smoking $(N=1,067)$

\begin{tabular}{|c|c|c|c|c|c|c|c|}
\hline Variables & $\begin{array}{c}\text { Total } \\
\mathrm{N}=1,067\end{array}$ & $\begin{array}{c}\text { Roll-your-own } \\
\text { cigarette } \\
n=496 \\
(48.6 \%)\end{array}$ & $\begin{array}{c}\text { Cigar, cigarillo } \\
n=517 \\
(50.6 \%)\end{array}$ & $\begin{array}{c}\text { Waterpipe } \\
n=863 \\
(82.0 \%)\end{array}$ & $\begin{array}{c}\text { Pipe } \\
n=181 \\
(18.9 \%)\end{array}$ & $\begin{array}{c}\text { Flavoured } \\
\text { cigarette } \\
n=668 \\
(64.4 \%)\end{array}$ & $\begin{array}{c}\text { Any ATP } \\
n=948 \\
(88.8 \%)\end{array}$ \\
\hline \multicolumn{8}{|c|}{ Demographic factors } \\
\hline \multicolumn{8}{|l|}{ Gender, n (\%) } \\
\hline Female & $598(56.0)$ & $264(45.6)$ & $215(37.5)^{*}$ & $472(80.0)$ & $53(9.8)^{*}$ & $379(65.1)$ & $529(88.5)$ \\
\hline Male & $469(44.0)$ & $232(52.5)$ & $302(67.4)$ & $391(84.4)$ & $128(30.5)$ & $289(63.5)$ & $419(89.3)$ \\
\hline \multicolumn{8}{|l|}{ Grade, n (\%) } \\
\hline 8th grade & $263(24.6)$ & $85(34.6)^{*}$ & $74(30.5)^{*}$ & $185(71.4)^{*}$ & $29(12.4)$ & $117(46.4)^{*}$ & $210(79.8)^{*}$ \\
\hline 11 th grade & $804(75.4)$ & $411(53.0)$ & $443(56.9)$ & $678(85.4)$ & $152(20.9)$ & $551(70.2)$ & 738 (91.8) \\
\hline \multicolumn{8}{|c|}{ Weekly allowance ${ }^{\mathrm{a}}, \mathrm{n}(\%)$} \\
\hline None & $296(28.3)$ & $136(47.1)$ & $138(48.1)$ & $236(80.5)$ & $42(15.3)$ & $162(55.9)$ & $263(88.9)$ \\
\hline$\leq 500$ HUF & $44(4.2)$ & $26(59.1)$ & $24(57.1)$ & $32(76.2)$ & $7(17.9)$ & $26(59.1)$ & $38(86.4)$ \\
\hline $501-1,000$ HUF & $180(17.2)$ & $71(41.0)$ & $80(47.3)$ & $130(73.9)$ & $28(17.4)$ & $105(60.3)$ & $150(83.3)$ \\
\hline $1,001-1,500$ HUF & $123(11.8)$ & $49(41.9)$ & $54(44.6)$ & $98(79.7)$ & $16(14.8)$ & $83(68.6)$ & $104(84.6)$ \\
\hline 1,501-2,000 HUF & $142(13.6)$ & $69(50.7)$ & $76(55.5)$ & $125(89.3)$ & $23(17.4)$ & $96(69.1)$ & $133(93.7)$ \\
\hline 2,001-3,000 HUF & $104(9.9)$ & $47(49.5)$ & $49(51.0)$ & $95(92.2)$ & $19(21.8)$ & $71(72.4)$ & $99(95.2)$ \\
\hline$\geq 3,001$ HUF & $157(15.0)$ & $87(59.2)$ & $87(58.4)$ & $132(85.2)$ & $41(29.7)$ & $112(74.2)$ & $143(91.1)$ \\
\hline \multicolumn{8}{|c|}{ Academic achievement, $n(\%)$} \\
\hline $2.00-2.50$ & $100(9.6)$ & $49(51.6)^{*}$ & $44(46.8)^{*}$ & $77(79.4)$ & $21(23.6)^{*}$ & $70(71.4)^{*}$ & $85(85.0)$ \\
\hline $2.51-3.00$ & $181(17.4)$ & $106(61.6)$ & $106(60.6)$ & $148(82.7)$ & $46(28.9)$ & $125(71.8)$ & $164(90.6)$ \\
\hline $3.01-3.50$ & $262(25.1)$ & $136(55.3)$ & $155(63.3)$ & $231(89.9)$ & $48(21.0)$ & $187(73.6)$ & $243(92.7)$ \\
\hline $3.51-4.00$ & $249(23.9)$ & $108(45.0)$ & $103(42.7)$ & $199(80.6)$ & $42(17.9)$ & $148(61.2)$ & $222(89.2)$ \\
\hline $4.01-4.50$ & $175(16.8)$ & $65(38.0)$ & $70(41.2)$ & $135(77.1)$ & $17(10.9)$ & $88(51.5)$ & $149(85.1)$ \\
\hline $4.51-5.00$ & $75(7.2)$ & $20(27.8)$ & $26(36.1)$ & $55(75.3)$ & $4(5.8)$ & $35(47.9)$ & $64(85.3)$ \\
\hline \multicolumn{8}{|l|}{ Social influences, n (\%) } \\
\hline Household smoking & $659(62.3)$ & $335(53.3)^{*}$ & $319(50.6)$ & $536(82.3)$ & $108(18.5)$ & $429(66.9)$ & $593(90.0)$ \\
\hline Smoking peers & $930(89.0)$ & $461(51.6)^{*}$ & $479(53.6)^{*}$ & $776(84.5)^{*}$ & $167(19.9)$ & $620(68.4)^{*}$ & $847(91.1)^{*}$ \\
\hline \multicolumn{8}{|c|}{ Manufactured cigarette use, $n(\%)$} \\
\hline $\begin{array}{l}\leq 12 \text { years old } \\
\text { when first tried a } \\
\text { cigarette }\end{array}$ & $343(32.1)$ & $196(58.9)^{*}$ & $189(56.9)$ & $277(81.5)$ & $79(25.8)^{*}$ & $235(69.3)$ & $299(87.2)$ \\
\hline $\begin{array}{l}\text { Smoked cigarette } \\
\text { in the past } 30 \text { days } \\
\text { (current smokers) }\end{array}$ & $584(65.7)$ & $395(69.9)^{*}$ & $382(67.3)^{*}$ & $515(89.6)^{*}$ & $139(26.5)^{\star}$ & $483(84.0)^{*}$ & $564(96.6)$ \\
\hline Ever smoked daily & 469 (52.9) & $345(76.7)^{*}$ & $336(74.5)^{*}$ & $421(91.3)^{*}$ & $121(29.5)^{*}$ & $400(87.1)^{*}$ & $460(98.1)$ \\
\hline
\end{tabular}


experimentation, $88.8 \%$ of ever manufactured cigarette users have ever tried also some kind of the surveyed ATPs. Any ATP experimentation was significantly higher among current smokers compared to non-current smokers $(96.6 \%$ vs. $83.9 \%$, respectively; $\left.\chi_{(1)}^{2}=44.72 ; \mathrm{p}<0.001\right)$ and among adolescents who have ever smoked daily for 30 days compared to never daily smokers $(98.1 \%$ vs. $85.9 \%$, respectively; $\left.\chi_{(1)}^{2}=46.59 ; \mathrm{p}<0.001\right)$. Waterpipe was the most popular product to try followed by flavoured cigarettes, cigars/cigarillos, RYO cigarettes, and pipe.

\section{Binary Logistic Regression Models to Explain Life- time Use of Each Specific ATP}

The impact of demographic, social influences and individual cigarette smoking variables on the lifetime use of specific ATPs were tested in five independent models (Table 2). Ever use of all surveyed ATPs had significantly greater odds in the older cohort. Females reported significantly lower likelihood ever trying most ATPs of which the odds of cigars/cigarillos and pipe experimentation were the lowest. Younger age of smoking initiation as well as more frequent past month cigarette smoking increased the odds of ever trying ATPs, except waterpipe. Participants exposed to household smoking reported lower odds of most ATP experimentation, although this association was significant only for cigar/ cigarillo use. The odds of ever trying waterpipe and flavoured cigarettes were more than two times greater among adolescents with smoking peers. Results also showed significant association between peer smoking and cigar/cigarillo experimentation. Higher weekly allowance was significantly and positively associated with trying flavoured cigarettes.

\section{Latent Class Analysis of Experimentations with ATPs}

Latent class analysis was performed on five binary indicators of experimentation with ATPs (RYO cigarette, cigar/cigarillo, waterpipe, pipe, and flavoured cigarette). Two-class to five-class solutions were estimated. Table 3 presents the information-based criteria, entropy for each solution, and the appropriate LMR test. The Akaike information criterion (AIC) decreased until 4-class solution, however, the Bayesian information criterion and samplesize adjusted BIC started to increase at 4-class model which would support the 3-class solution. In support for the 4-class solution, Lo-Mendell-Rubin adjusted likelihood ratio test became nonsignificant only at 5-class model. Inspecting the statistics and

Table 2. Multivariable logistic regression models to explain experimentation of each specific alternative tobacco product $(N=1,067)$

\begin{tabular}{|c|c|c|c|c|c|c|c|c|c|c|}
\hline \multirow{2}{*}{ Variables } & \multicolumn{2}{|c|}{ Roll-your-own } & \multicolumn{2}{|c|}{ Cigar, cigarillo } & \multicolumn{2}{|c|}{ Waterpipe } & \multicolumn{2}{|c|}{ Pipe } & \multicolumn{2}{|c|}{ Flavoured cigarettes } \\
\hline & OR & $95 \% \mathrm{Cl}$ & OR & $95 \% \mathrm{Cl}$ & OR & $95 \% \mathrm{Cl}$ & OR & $95 \% \mathrm{Cl}$ & OR & $95 \% \mathrm{Cl}$ \\
\hline \multicolumn{11}{|l|}{ Grade } \\
\hline 11th grader & 1.70 & $1.10-2.62$ & 3.32 & $2.08-5.30$ & 1.91 & $1.19-3.07$ & 1.75 & $0.99-3.09$ & 2.37 & $1.54-3.65$ \\
\hline 8th graders & 1.00 & & 1.00 & & 1.00 & & 1.00 & & 1.00 & \\
\hline \multicolumn{11}{|l|}{ Gender } \\
\hline Male & 1.92 & $1.37-2.70$ & 6.78 & $4.62-9.97$ & 1.54 & $0.99-2.38$ & 4.97 & $3.28-7.54$ & 1.18 & $0.82-1.69$ \\
\hline Female & 1.00 & & 1.00 & & 1.00 & & 1.00 & & 1.00 & \\
\hline Weekly allowance ${ }^{a}$ & 0.95 & $0.88-1.02$ & 0.94 & $0.86-1.01$ & 1.07 & $0.97-1.19$ & 1.04 & $0.95-1.14$ & 1.10 & $1.01-1.19$ \\
\hline $\begin{array}{l}\text { School academic } \\
\text { achievementa }\end{array}$ & 1.02 & $0.91-1.16$ & 1.12 & $0.98-1.27$ & 1.09 & $0.94-1.27$ & 0.90 & $0.77-1.06$ & 1.04 & $0.91-1.19$ \\
\hline \multicolumn{11}{|l|}{ Household smoking } \\
\hline Yes & 1.17 & $0.82-1.67$ & 0.67 & $0.46-0.98$ & 0.96 & $0.61-1.50$ & 0.67 & $0.44-1.03$ & 0.78 & $0.53-1.14$ \\
\hline No & 1.00 & & 1.00 & & 1.00 & & 1.00 & & 1.00 & \\
\hline \multicolumn{11}{|l|}{ Peer smoking } \\
\hline$\geq 1$ smoking friends & 1.50 & $0.80-2.79$ & 2.01 & $1.03-3.94$ & 2.88 & $1.60-5.19$ & 0.74 & $0.32-1.70$ & 2.29 & $1.28-4.07$ \\
\hline No smoking friend & 1.00 & & 1.00 & & 1.00 & & 1.00 & & 1.00 & \\
\hline $\begin{array}{l}\text { Cigarette smoking } \\
\text { frequency in the past } \\
\text { month }^{a}\end{array}$ & 1.23 & $1.12-1.34$ & 1.25 & $1.14-1.38$ & 1.10 & $0.97-1.24$ & 1.17 & $1.04-1.32$ & 1.31 & $1.19-1.45$ \\
\hline \multicolumn{11}{|l|}{ Age of smoking onset } \\
\hline$\leq 12$ years old & 2.19 & $1.52-3.17$ & 2.26 & $1.52-3.34$ & 0.96 & $0.61-1.51$ & 2.31 & $1.51-3.55$ & 1.46 & $0.98-2.18$ \\
\hline$\geq 13$ years old & 1.00 & & 1.00 & & 1.00 & & 1.00 & & 1.00 & \\
\hline \multicolumn{11}{|l|}{ Ever daily smoking } \\
\hline Yes & 2.85 & $1.86-4.35$ & 2.72 & $1.72-4.32$ & 1.66 & $0.92-2.99$ & 1.67 & $0.93-2.99$ & 1.83 & $1.14-2.93$ \\
\hline Never & 1.00 & & 1.00 & & 1.00 & & 1.00 & & 1.00 & \\
\hline $\mathrm{R}^{2}$ & $30 \%$ & & $40 \%$ & & $12 \%$ & & $25 \%$ & & $27 \%$ & \\
\hline
\end{tabular}

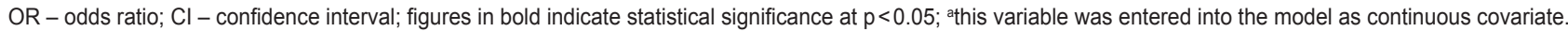


Table 3. Fit indices for latent profile analysis of alternative tobacco product experimentation $(N=1,067)$

\begin{tabular}{|l|c|c|c|c|c|c|}
\hline Number of latent classes & AIC $^{\mathrm{a}}$ & BIC $^{\mathrm{b}}$ & SSABIC & Entropy & LMR test $^{\mathrm{d}}$ & p-value $^{\mathrm{e}}$ \\
\hline 2 classes & 5156.1 & 5210.8 & 5175.9 & 0.756 & 948.2 & $<0.001$ \\
\hline 3 classes & 5063.4 & 5147.9 & 5093.9 & 0.721 & 102.3 & $<0.001$ \\
\hline 4 classes & 5053.7 & 5168.0 & 5095.0 & 0.649 & 21.2 & 0.009 \\
\hline 5 classes & 5061.9 & 5206.1 & 5114.0 & 0.686 & 3.6 & 0.215 \\
\hline
\end{tabular}

${ }^{a} \mathrm{AIC}$ - Akaike information criterion; ${ }^{\mathrm{b}} \mathrm{BIC}$ - Bayesian information criterion; ' $\mathrm{SSABIC}$ - sample size adjusted Bayesian information criterion; ${ }^{\mathrm{d}} \mathrm{LMR}$ test - Lo-Mendell-Rubin adjusted likelihood ratio test value; ep-value associated with LMR test.

meanings of classes, we accepted the 4-class solution. Latent classes are presented in Figure 1. The most populous class was Class $2(38.4 \%)$ reflecting intense polytobacco experimentation with almost all ATPs. The second largest class was Class 1 (34.2\%) representing very large proportion of waterpipe experimentation with some flavoured cigarette and cigar/cigarillo trial. Class 3

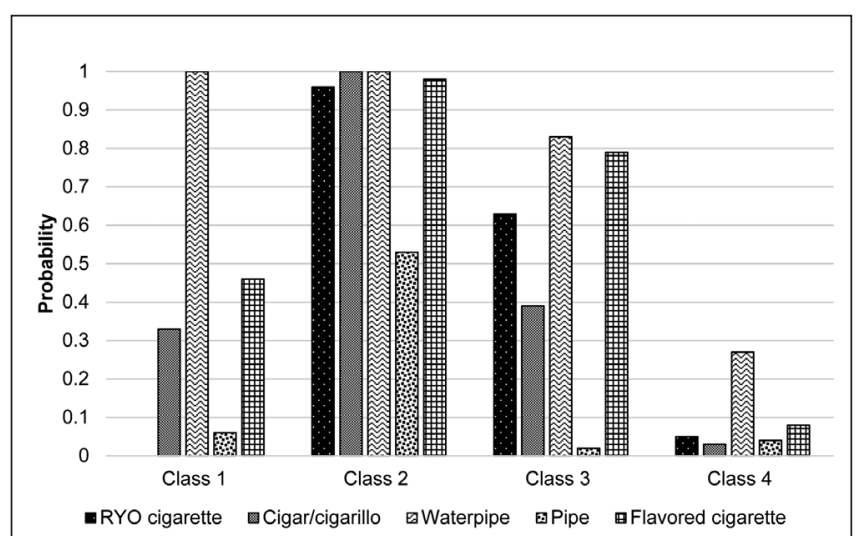

Fig. 1. Latent classes of alternative tobacco product experimentation patterns.

Class 1 - mainly waterpipe experimenters $(\mathrm{N}=365)$; Class 2 - intense polytobacco experimenters $(\mathrm{N}=410)$; Class 3 - moderate polytobacco experimenters $(N=133)$ Class 4 - less interested experimenters $(\mathrm{N}=159) ; \mathrm{Y}$ axis represents the probability scale; estimated $\mathrm{N}$ is based on the most likelihood latent class membership.
$(12.5 \%)$ represents general, but moderate polytobacco experimentation with the exception of pipe. Class 4 (14.9\%) collects students who mainly did not tried ATPs, however, we could also observe a low intensity experimentation with waterpipe.

In order to compare the four classes, we performed a multinomial regression analysis with Class 4 (less interested experimenters) as a reference group. Odds ratios are presented in Table 4. Students belonging to Class 2 (intense polytobacco experimenters) were more likely boys, older students, having at least one friend who smokes cigarette, smoked during the past 30 days and ever smoked daily compared to Class 4 . Students belonging to Class 1 (mainly waterpipe experimenters) are more likely to be older and have at least one smoking friend compared to Class 4. The only difference between Class 3 (moderate polytobacco experimenters) and Class 4 was in current smoking, thus, students in Class 3 smoked more likely cigarette during the past 30 days than students in Class 4.

\section{DISCUSSION}

This study explored the simultaneous effect of individual cigarette smoking patterns, social smoking influences and demographic factors on the experimentation of alternative tobacco products in a sample of Hungarian metropolitan adolescents who have ever tried manufactured cigarette smoking. In Europe, only few studies have measured correlates of specific types of ATP use

Table 4. Multinomial logistic regression analysis to predict latent class categories (latent class with covariates analysis, $N=1,067$ )

\begin{tabular}{|c|c|c|c|c|c|c|c|c|c|}
\hline \multirow[t]{2}{*}{ Covariates $^{\mathrm{a}}$} & \multicolumn{3}{|c|}{$\begin{array}{l}\text { Class } 1 \text { (mainly waterpipe experi- } \\
\text { menters), } n=365\end{array}$} & \multicolumn{3}{|c|}{$\begin{array}{c}\text { Class } 2 \text { (intense polytobacco experi- } \\
\text { menters), } n=410\end{array}$} & \multicolumn{3}{|c|}{$\begin{array}{c}\text { Class } 3 \text { (moderate polytobacco } \\
\text { experimenters), } n=133\end{array}$} \\
\hline & OR & $95 \% \mathrm{Cl}$ & $\mathrm{p}$ & OR & $95 \% \mathrm{Cl}$ & $\mathrm{p}$ & OR & $95 \% \mathrm{Cl}$ & $p$ \\
\hline Gender (boys/girls) & 1.04 & $0.40-2.71$ & 0.421 & 0.21 & $0.10-0.44$ & $<0.001$ & 1.29 & $0.57-2.95$ & 0.449 \\
\hline Grade (8th/11th) & 1.28 & $0.90-1.81$ & 0.047 & 1.91 & $1.43-2.53$ & $<0.001$ & 1.10 & $0.84-1.44$ & 0.479 \\
\hline Weekly allowance ${ }^{b}$ & 1.04 & $0.85-1.27$ & 0.993 & 1.05 & $0.89-1.25$ & 0.403 & 0.95 & $0.78-1.16$ & 0.773 \\
\hline School achievement ${ }^{b}$ & 1.22 & $0.85-1.74$ & 0.202 & 1.15 & $0.86-1.55$ & 0.675 & 1.15 & $0.84-1.59$ & 0.571 \\
\hline Household smoking (no/yes) & 1.07 & $0.47-2.45$ & 0.712 & 1.18 & $0.57-2.48$ & 0.992 & 1.57 & $0.70-3.55$ & 0.457 \\
\hline Smoking friends (none/ $\geq 1$ ) & 16.74 & $1.11-251.64$ & 0.002 & 3.57 & $1.26-10.08$ & 0.044 & 3.06 & $1.05-8.96$ & 0.207 \\
\hline $\begin{array}{l}\text { Age of smoking onset }(\leq 12 \\
\text { years old } / \geq 13 \text { years old })\end{array}$ & 2.91 & $0.92-9.22$ & 0.074 & 0.49 & $0.22-1.07$ & 0.040 & 1.02 & $0.44-2.35$ & 0.925 \\
\hline $\begin{array}{l}\text { Smoked cigarettes in the past } \\
30 \text { days }^{b}\end{array}$ & 1.06 & $0.81-1.39$ & 0.084 & 1.42 & $1.13-1.78$ & $<0.001$ & 1.29 & $1.01-1.64$ & $<0.001$ \\
\hline Ever daily smoking (no/yes) & 1.00 & $0.32-3.13$ & 0.794 & 0.21 & $2.38-16.18$ & $<0.001$ & 2.11 & $0.71-6.27$ & 0.056 \\
\hline
\end{tabular}

aReference categories are always in the first place; bthis variable was entered into the model as continuous covariate; multinomial logistic regression analysis was performed by the three-step procedure implemented in Mplus 8.00 (25). The reference group was Class 4 (low intensity experimenters). 
among adolescents $(16,20-23)$ and only one study from Romania have examined the lifetime use of wide range of different ATPs (19). In our sample, almost $90 \%$ of lifetime cigarette smokers reported ever trial of any ATP. Comparing multiple ATP experimentation in the few existing studies, waterpipe experimentation and other flavoured products like e-cigarettes experimentation were common likewise in our study, which however assessed only flavoured cigarette use disregarding e-cigarettes due to the novelty of this product at the time of data collection $(11,19)$. Latent class analysis identified four meaningful subgroups of ATP experimenters. Intense polytobacco experimentation was a usual pattern of almost $40 \%$ of students who have ever tried cigarette smoking and were more established cigarette smokers. Waterpipe experimentation was relatively frequent in all classes and one third of respondents belonged to the mainly waterpipe experimenter group who were less established smokers but had some smoking peers. Our findings are in concordance with other studies detecting multiple and selective ATP experimenter groups among adolescents with similar cigarette smoking differences across groups $(11,19)$. These findings indicate high curiosity toward ATPs and especially for flavoured products like waterpipe, flavoured cigarettes and recently e-cigarettes available in many attractive flavours. Additionally, high experimentation rates suggest that these products were easily accessible to youth.

Similarly to the majority of previous studies that found differences in ATP use by sex, adolescent girls were less likely to report ever trial of ATPs except flavoured cigarettes (2, 3, 9, 11, 13, 14, 19). Additionally, we found that current cigarette smokers were significantly more likely to try ATPs than non-smokers. Our result is consistent with previous US studies which detected a strong association between ever and current cigarette smoking and ATP use in adolescence $(3,9,13,14)$. Outside the USA, a study among Latin American adolescents in Argentina found that almost half of participants who ever smoked manufactured cigarettes tried any ATP compared to $2.9 \%$ of never smokers (2), while among adolescents in central Romania, the prevalence of different ATP experimentation ranged between $6.9-74.4 \%$ among ever cigarette smokers, compared to $0.5-8.0 \%$ of never smokers (19).

Similarly to previous research, our results provide additional evidence that early cigarette smoking experimentation, greater cigarette smoking frequency and ever daily smoking were positively related to any ATP use as well as intense multiple ATP use $(9,13,19)$. Additionally, more established cigarette smoking characteristics increased the likelihood of almost all specific ATP ever trial, except experimentation with waterpipe. Based on the high prevalence of waterpipe experimentation in our sample, the lack of association with established cigarette smoking, and the robust impact of peer smoking on waterpipe ever use in the identified subgroup (Class 1) of ATP experimenters, we assume that waterpipe smoking is widely popular among both current and non-current smoker adolescents in Hungary. A recent systematic review found that adolescents' main motives for hookah use are peer pressure, curiosity, socializing, fashion, relaxation, and the lack of perceived harmful effects of its use (26).

The impact of social influences on adolescent cigarette smoking initiation and maintenance is well documented (27). By contrast, familial and peer influences on ATP use are understudied and contradictory. Similarly to previous findings, ever trying of any ATPs mostly was not associated with household smoking exposure among Hungarian adolescents $(2,8,13,14,19,21$, 28). However, the only exception was cigar and cigarillo use, adolescents living in a smoke-free household were more likely to report ever trial of these products. An explanation for this result could be that youth perceive cigars more natural and therefore less harmful than manufactured cigarettes (29). Our finding that peer smoking had an impact on specific (waterpipe, flavoured cigarettes and cigars/cigarillos) and multiple ATP experimentation is parallel to the previous studies that explored strong association between ATP use and peer cigarette smoking exposure (2, 3, 13, 18). Only a few studies have explored simultaneously the impact of peer cigarette smoking on specific ATP use confirming that it had a greater effect on cigar $(2,13)$ and waterpipe (19) use than on other ATPs.

School academic achievement did not have an impact on ATP experimentation in our sample, although some previous studies found that US adolescents who used different ATPs were more likely to have lower self-reported marks than non-users (28). Likewise Nasim et al., we found no association between adolescents allowance and ATP experimentation except for flavoured cigarettes (13). Youth are more price-sensitive than adults, however, it is likely that cigarette prices have different effects on adolescent smoking depending on whether they are social or regular smokers (30). Our results provide additional evidence that individuals in the experimentation stage of tobacco use will likely be less affected by price concerns because they often do not purchase their own tobacco products (30).

The present study has some limitations that need to be acknowledged. The cross-sectional design precludes our ability to assess causality and decreases our ability to control for unmeasured confounding variables. Second, self-reported nature is prone to respondent bias, and biochemical validation was not feasible in this study. Another limitation is that only ever cigarette experimenters responded to questions related to ATP experimentation, therefore, we were not able to explore ATP experimentation among never smoker adolescents. Finally, e-cigarettes and smokeless tobacco products experimentation were not assessed in this study because e-cigarettes were novel and uncommonly used products at the time of data collection, while the prevalence of adolescents' smokeless tobacco product use is negligible because the sale of these products is illegal in Hungary.

\section{CONCLUSIONS}

This study provides more insight to factors underlying ATP experimentation among Central European youth, a population that had little representation so far in the scientific literature. The majority of lifetime cigarette smoker adolescents reported ever use of any ATP of which waterpipe was the most popular product to try followed by flavoured cigarettes, cigars and cigarillos, RYO cigarettes, and pipe. Experimentation with ATPs was mostly associated with male sex, younger age of smoking initiation, current smoking and smoker best friends. Our study also identified subgroups of ATP experimenters of which intense polytobacco and mainly waterpipe experimenter groups were the most populous groups. These findings highlight that tobacco prevention programmes should address the risks of using ATPs in addition to manufactured cigarettes and pay particular attention to waterpipe 
usage which is common among all clusters of ATP experimenters. Interventions should target specific vulnerable segments of adolescents that have the greatest risk for polytobacco use. Existing comprehensive regulations of tobacco products should be strictly enforced in order to prevent youth from potential harmful consequences of polytobacco use. Further studies need to monitor ATP use in younger and older adolescents and confirm our findings in the Central European region.

\section{Acknowledgements}

This work was supported by the Fogarty International Center, the National Cancer Institute, and the National Institute on Drug Abuse, within the National Institutes of Health (Grant Number 1 R01 TW007927-01). Its contents are solely the responsibility of the authors and do not necessarily represent the official view of the National Institutes of Health.

\section{Conflict of Interests}

None declared

\section{Adherence to Ethical Standards}

All consent documents and research protocols/study procedures were approved by the Semmelweis University Regional and Institutional Committee of Science and Research Ethics.

\section{REFERENCES}

1. O'Connor RJ. Non-cigarette tobacco products: what have we learnt and where are we headed? Tob Control. 2012;21(2):181-90.

2. Alderete E, Kaplan CP, Gregorich SE, Pérez-Stable EJ. Use of alternative tobacco products in multiethnic youth from Jujuy, Argentina. J Environ Public Health. 2010;2010:795265. doi: 10.1155/2010/795265.

3. Tercyak KP, Audrain J. Psychosocial correlates of alternate tobacco product use during early adolescence. Prev Med. 2002;35(2):193-8.

4. El-Toukhy S, Choi K. A risk-continuum categorization of product use among US youth tobacco users. Nicotine Tob Res. 2016;18(7):1596-605.

5. National Center for Chronic Disease Prevention and Health Promotion (US), Office on Smoking and Health. Preventing tobacco use among youth and young adults: A report of the Surgeon General [Internet]. Atlanta: CDC; 2012 [cited 2016 Feb 24]. Available from: http://www.ncbi.nlm. nih.gov/books/NBK99237/.

6. Lauterstein D, Hoshino R, Gordon T, Watkins B-X, Weitzman M, Zelikoff J. The changing face of tobacco use among United States youth. Curr Drug Abuse Rev. 2014;7(1):29-43.

7. Amrock SM, Weitzman M. Alternative tobacco products as a second front in the war on tobacco. JAMA. 2015;314(14):1507-8.

8. Saunders C, Geletko K. Adolescent cigarette smokers' and non-cigarette smokers' use of alternative tobacco products. Nicotine Tob Res. 2012;14(8):977-85.

9. Nasim A, Blank MD, Cobb CO, Eissenberg T. Patterns of alternative tobacco use among adolescent cigarette smokers. Drug Alcohol Depend. 2012;124(1-2):26-33.

10. Soldz S, Dorsey E. Youth attitudes and beliefs toward alternative tobacco products: cigars, bidis, and kreteks. Health Educ Behav. 2005;32(4):54966.
11. Gilreath TD, Leventhal A, Barrington-Trimis JL, Unger JB, Cruz TB, Berhane K, et al. Patterns of alternative tobacco product use: Emergence of hookah and e-cigarettes as preferred products amongst youth. J Adolesc Health. 2016;58(2):181-5.

12. Carpenter CM, Wayne GF, Pauly JL, Koh HK, Connolly GN. New cigarette brands with flavors that appeal to youth: Tobacco marketing strategies. Health Aff (Millwood). 2005;24(6):1601-10.

13. Nasim A, Blank MD, Cobb CO, Eissenberg T. A Multiple indicators and multiple causes model of alternative tobacco use. Am J Health Behav. 2013;37(1):25-31.

14. Gilpin EA, Pierce JP. Concurrent use of tobacco products by California adolescents. Prev Med. 2003;36(5):575-84

15. Cole AG, Leatherdale ST, Rynard VL. Roll-your-own tobacco use among Canadian youth: current prevalence and changes in youth smoking "rollies" since 2008. Chronic Dis Inj Can. 2014;34(4):263-9.

16. Gallus S, Lugo A, Colombo P, Pacifici R, La Vecchia C. Smoking prevalence in Italy 2011 and 2012, with a focus on hand-rolled cigarettes. Prev Med. 2013;56(5):314-8.

17. Demjén T, Kiss J, Formanek-Balku E. World Health Organization, Global Youth Tobacco Survey, Hungary, 2016 [Internet]. Budapest: Hungarian Focal Point for Tobacco Control; 2016 [cited 2017 Dec 7]. Available from: http://www.fokuszpont.dohanyzasvisszaszoritasa.hu/sites/default/ files/01 GYTS 2016 osszefoglalo tanulmany.pdf. (In Hungarian.)

18. Bombard J, Rock V, Pederson L, Asman K. Monitoring polytobacco use among adolescents: Do cigarette smokers use other forms of tobacco? Nicotine Tob Res. 2008;10(11):1581-9.

19. Nădăşan V, Foley KL, Pénzes M, Paulik E, Mihăicuţă Ş, Ábrám Z, et al. Use of electronic cigarettes and alternative tobacco products among Romanian adolescents. Int J Public Health. 2016;61(2):199-207.

20. Raisamo SU. Trends in roll-your-own tobacco use among adolescents in Finland, 1981-2009. Prev Med. 2011;53(6):431-2.

21. Jensen PD, Cortes R, Engholm G, Kremers S, Gislum M. Waterpipe use predicts progression to regular cigarette smoking among Danish youth. Subst Use Misuse. 2010;45(7-8):1245-61.

22. Jawad M, Wilson A, Lee JT, Jawad S, Hamilton FL, Millett C. Prevalence and predictors of water pipe and cigarette smoking among secondary school students in London. Nicotine Tob Res. 2013;15(12):2069-75.

23. Pärna K, Usin J, Ringmets I. Cigarette and waterpipe smoking among adolescents in Estonia: HBSC survey results, 1994-2006. BMC Public Health. 2008;8:392. doi: 10.1186/1471-2458-8-392.

24. Collins LM, Lanza ST. Latent class and latent transition analysis: with applications in the social, behavioral, and health sciences. Hoboken: John Wiley \& Sons; 2009.

25. Muthén LK, Muthén BO. Mplus user's guide. 8th ed. Los Angeles: Muthén \& Muthén; 2017.

26. Akl EA, Jawad M, Lam WY, Co CN, Obeid R, Irani J. Motives, beliefs and attitudes towards waterpipe tobacco smoking: a systematic review. Harm Reduct J. 2013;10:12. doi: 10.1186/1477-7517-10-12.

27. Tyas SL, Pederson LL. Psychosocial factors related to adolescent smoking: a critical review of the literature. Tob Control. 1998;7(4):409-20.

28. Brooks A, Gaier Larkin EM, Kishore S, Frank S. Cigars, cigarettes, and adolescents. Am J Health Behav. 2008;32(6):640-9.

29. Malone RE, Yerger V, Pearson C. Cigar risk perceptions in focus groups of urban African American youth. J Subst Abuse. 2001;13(4):549-61.

30. Nikaj S, Chaloupka FJ. The effect of prices on cigarette use among youths in the Global Youth Tobacco Survey. Nicotine Tob Res. 2014;16 Suppl 1:S16-23. 